\title{
Preparation, Spectroscopic and Mechanical Studies of Nano Porous HAp Loaded with MWCNTs
}

\author{
G. S. El-Bahy ${ }^{1}$, Y. M. Abbas' ${ }^{2}$ A. M. Hezma*1, N. M. Gweily ${ }^{1}$ \\ ${ }^{1}$ Spectroscopy Department, Physics Research Division,National Research Centre, \\ Dokki, Cairo, 12622, '2 Physics Department, Faculty of Science, Suez Canal University, \\ Ismailia, 41522, Egypt.
}

\begin{abstract}
T HE MAIN purpose of this study was to prepare and characterize porous Hydroxyapatite (HAp) with controllable pore size using different additions of synthetic polymer. Porous HAp was doped with MWCNTs with different concentrations to enhance its mechanical properties to match human hard tissues engineering. In-situ synthesized of pure nano-HAp, PVA and MWCNTs were analyzed using different characterization techniques. Phase analysis was analyzed by the room temperature powder X-ray diffraction (XRD); Fourier transform infrared spectroscopy (FTIR) is particularly useful for the identification of chemicals substances that are either organic or inorganic. The size of the prepared nano HAp powder detected using high resolution transmission electron microscopy (HR-TEM). Morphology and microstructure of porous ceramics were examined using scanning electron microscopy (SEM). The stress-strain test was examined to determine mechanical properties for the prepared samples. Experimental results indicated that the $10 \%$ PVA is found to impregnate the porous ceramics effectively with uniform size distributions with pore sizes around $100 \mathrm{~nm}$. The physical and mechanical analysis were clearly enhanced after MWCNTs additions to porous HAp. According to the previous such porous materials should be suitable materials for load sharing tissue-engineering applications
\end{abstract}

Keywords: Porous HAp, MWCNTs, XRD and Mechanical properties.

\section{Introduction}

Biomaterials on the basis of ceramics have been widely used in recent decades for medical application [1, 2]. The definition of bioceramics is biomaterials of ce-ramic classification that are "specially fabricated and designed For the reform parts of the body and reconstruction [3] of damaged, diseased, missing or worn out parts of the body" $[4,5]$. Bioceramics can be divided into resorbable and bioactive (i.e. Hydroxyapatite and Biological glasses), bioinert (i.e., Alumina, zirconia), or can stimulate cell specific responses at the molecular level as scaffold for tissue engineering $[1,6]$. Among the ceramic materials usually used for biomedical applications, hydroxyapatite (HAp).HAp is a mineral family apatite and dominant inorganic phase in natural bone. It is similar to human hard tissues where Human bones mainly contain »70 wt.\% apatite, 10 wt. $\%$ water, and 20 wt. Collagen[4, 7]. As a result of these, the Hydroxyapatite has attracted considerable attention from researchers [8-11]. The chemical formula of HAp is $\mathrm{Ca}_{5}\left(\mathrm{PO}_{4}\right)_{3}(\mathrm{OH})$ and the formula of unite cell of hydroxyapatite is (HAp, $\mathrm{Ca}_{10}(\mathrm{PO} 4)_{6}(\mathrm{OH})_{2}$. Chemical precipitation method of nano-sized powders from salt solutions is among the simplest techniques for rapid synthesis of large amounts of HAp in a controlled manner [12-14]. The process parameters have been optimized to produce high purity hydroxyapatite. At the first, the synthetic HAp as biomaterials used in the form of dense matter but in the advance researches the used of HAp in the form of porous matter was preferred. they found that porous HAp have better bioresorption, bioactivity and corrosion resistance as bone implant and scaffolding make it easy to form a direct bond with adjacent bone [15-22]. Various methods have been developed to synthesize porous HAp. Among these methods, wet chemical process was generally used to prepare porous HAp powder and

*Corresponding author: E-mail address: ahezma@yahoo.com

DOI: 10.21608/JTCPS.2019.14600.1023

(C)2019 National Information and Documentation Centre (NIDOC) 
polymer as binder because it is a simple and variety economic route. Besides the above during the reactions, the reaction media involves no foreign elements except water, the only by product. For these reasons, it is of great importance to develop inexpensive porous HAp synthesis methods focused on the precise control of particle size, morphology and chemical composition $[12,23]$. Therefore, it is always desirable to record from a high degree of crystallinity and chemical stability under the qualifications of a porous hydroxyapatite ideal $[24,25]$.The main drawbacks of porous HAp are its fragility, low fracture strength, low mechanical reliability, difficulty of fabrication and high density[26]. So the strategy to overcome this weakness is to introduce materials possess good mechanical properties to enhance mechanical properties with HAP as matrix without impairing its bioactivity. Carbon nanotubes have a lot of interest in most of the areas of nanoscience and nanotechnology because of their high chemical and thermal stability, mechanical resistance, flexibility, electrical and thermal conductivity [27-29]. Inclusion of small amounts of CNTs in a ceramic matrix should that producing composites with high rigidity and mechanical properties improved compared to single phase ceramics. The main purpose of this study was to prepare and characterize porous HAp using different additions of synthetic polymer to control pore size of HAp. MWCNTs used to enhance mechanical properties of the prepared porous scaffold to match human hard tissues structural and properties.

\section{Experimental details}

\section{Materials}

The chemicals used were Calcium Nitrate 4-hydrateGR [Ca(NO3)2.4H2O] from Alpha chemika, $\mathrm{Mw}=236.15$ Ammonium phosphate, dibasic [(NH4)2HPO4] from NSF With $\mathrm{Mw}=$ 132.06. Ammonia solution $25 \%$ with $\mathrm{Mw}=17.03$. Poly vinyl Alcohol Extra pure $\left(-\mathrm{C}_{2} \mathrm{H}_{4} \mathrm{O}\right)_{\mathrm{n}}$ from Alpha chemika, India with $\mathrm{Mw}=115000$ (lot No. AL6363). Carbon nanotubes, multi-wall (MWCNTs) of diameter 140nm, Length 7microns from Streem chemical (lot No. B0981067)

\section{Methods \\ Preparation of HAp by chemical method}

In this study the HAp powder was synthesized by wet precipitation method[30]. The analytical reagent grade Calcium nitrate tetra hydrate and Ammonium phosphate dibasic was used as the starting materials. To maintain molar ratio of Ca:P at 1.67 (constant) the amount of the precursors were calculated [31]. It is substantial for biological response to produce pure HAp without minor fraction. The prepared solution of ammonium phosphate dibasic was added slowly to prepared solution of calcium nitrate with vigorous stirring. As a result of this a turbid solution was formed. The PH was maintained at high value around $10-11$ by adding ammonia solution and stirred continuously for about 1 hour at $80^{\circ} \mathrm{C}$ until white precipitate was obtained. The solution stirred continuously for about $24 \mathrm{hr}$ without heating and left for overnight (aging) to settle precipitate and remove ammonia by washing the precipitate many times with distilled water and centrifuged by high speed centrifuge. The substance calcined at $900{ }^{\circ} \mathrm{C}$ for 4 hours. The obtained powder was grinded by agate mortar to obtain the resultant fine powder. The powder characterized by FTIR, XRD, TEM and SEM to study the physical and morphological properties of prepared nano-HAp.

\section{Preparation of HAp and PVA biocomposite}

Biocomposite materials based on hydroxyapatite powder reinforced with polymer matrix to obtain biodegradation, Porosity and mechanical property are the typical concern while preparing biocomposite[32]. Set of PVA/HAp composite were synthesized by employing freeze drying technique. Four different concentrations of PVA were prepared by dissolving it in distilled water at $80^{\circ} \mathrm{C}$ for 1 hour with different ratio $(5 \%$, $10 \%, 15 \%$ and $20 \%$ ). 1 gmof HAp powder was synthesized and added to the PVA solution with vigorous stirring for overnight by a magnetic stirrer to obtain better distribution of HAp powder in the PVA solution. Composites were casted in bettrei dish and kept at $-180{ }^{\circ} \mathrm{C}$ for overnight, (freeze drying). The resultant powders were crushed by ball milling to obtain fine powder and pressured at 60-65 MPa by uni-axial pressing into cylindrical samples of $0.5 \mathrm{~cm}$ diameter forming disc as shown in figure (1).Then the four samples discs put in oven for burning at $500{ }^{\circ} \mathrm{C}$ for 2 hours to obtain porous HAp. Physical and mechanical characteristics were performed to choose the best porous HAp for reinforcing with MWCNTs.

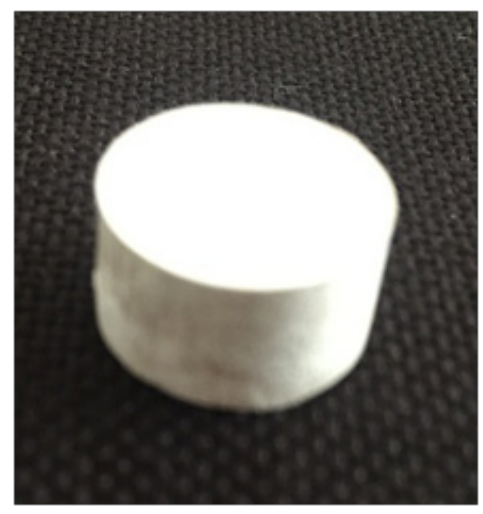

Fig.1. HAp disc. 
Preparation of HAp/MWCNTs bioceramic

Set of 10\%PVA-HAp/MWCNT composites were synthesized as follows: PVA was dissolved in distilled water at $80^{\circ} \mathrm{C}$ for 1 hour with concentration of $10 \%$ ( from result this is the best ratio of prepared HAp/PVA composite that gives us suitable porous HAp). Four different concentrations of MWCNTs were added and sonicated (Vibracell Sonics, 750 W) during 30 minutes. The MWCNTs were doped in PVA solutions with concentrations of $(0.0005$, $0.001,0.002$ and, 0.003)g. $1 \mathrm{~g}$ of synthesized HAp powder was added to the PVA-MWCNTs solution with vigorous stirring for overnight by a magnetic stirrer to obtain a better distribution of HAp powder in the PVA-MWCNT solution. Composites were casted in bettri dish and dried at $40^{\circ} \mathrm{C}$ for overnight. The resultant powders were crushed by ball milling to obtain fine powder and pressured at $60-65 \mathrm{MPa}$ by uni-axial pressing into cylindrical samples of $5 \mathrm{~cm}$ diameter forming discs. Then four discs were burned at $500{ }^{\circ} \mathrm{C}$ for 2 hrto obtain porous HAp with MWCNTs.

\section{Characterization techniques}

Prepared samples were characterized by XRD, Phase analysis was analyzed by the room temperature powder X-ray diffraction using EMPYREAN X-ray diffractometer with monochromatic $\mathrm{Cu} \mathrm{K} \alpha$ radiation of $\lambda=1.5406 \mathrm{~A}^{\circ}$, scan axis Gonio and scan range $(2 \mathrm{q})$ of $4^{\circ}$ to $90^{\circ}$ at $30 \mathrm{~mA}, 45 \mathrm{kV}[26]$ Fourier Transform Infrared Spectroscopy (FTIR) spectroscopy is particularly useful for the identification of chemicals substances that are either organic or inorganic. The term Fourier Transform Infrared Spectroscopy refers to a fairly recent development of the way in which data are collected and transformed from an interference figure into a spectrum. The wavelength range 4000-400 $\mathrm{cm}^{-1}$ using a computerized recording FTIR spectrometer (Matt-son5000, USA). Finely powdered samples were mixed with $\mathrm{KBr}$ in the ratio $1: 100$ for quantitative analysis and the weight. Morphology and EDX analysis were examined under SEM Philips apparatus, USA, type QUANTA FEG 250 and Cambridge type 590. The morphology of the prepared hydroxyapatite nanoparticles was detected using high resolution transmission electron microscopy (TEM). HR-TEM observation was carried out using TEM model JEOL 2100 transmission electron microscope. The mechanical properties of prepared samples were analyzed using the compressive stress strain test on a universal testing machine (L.loyd Instruments Ltd, UK).
Each sample was scanned at a cross head speed of two $\mathrm{mm} / \mathrm{min}$ at room temperature. Three measurements were performed at least for each sample and the mean values were reported.

\section{$\underline{\text { Results and discussion }}$}

Pure nano-HAp

The X-ray diffraction was considered as fingermark for the compound structure. X-Ray diffraction of the pure HAp was done to obtain information on the nature of the crystalline phases present in the pure HAp. Fig.(2) shows the XRD pattern of the pure HA powder that the characteristic peaks of HAp were located at $25.9^{\circ}, 31.7^{\circ}, 32.2^{\circ}, 32.9^{\circ}, 34.1^{\circ}, 39.7^{\circ}, 46.7^{\circ}$, $49.5^{\circ}$ and the values assigned to the Miller's indices of reflection plane are (002), (211), (112), (300), (202), (130), (222) and (213) respectively. The $\mathrm{d}$ value is the most important parameter in the conformation of the structure of a compound where $d$ is the distance between atomic planes in a crystal. The observed positions of the diffraction lines ( $2 \theta$ and corresponding $\mathrm{d}_{2 \theta}$ ) and their relative intensities $\left(\mathrm{I}_{\text {rel }}\right)$ are listed in Table 1. According to an equation derived from Bragg law the $\mathrm{d}_{2 \theta}$ values were calculated [33-35].

$$
\mathrm{d}(\mathrm{nm})=0.154 / 2 \operatorname{Sin} \theta
$$

where $\theta$ is the angle between the incident X-ray beam and crystal surface layer planes. The relative intensities of the diffraction lines were obtained as diffraction line heights relative to the most intense line normalized to the intensity of 100 .

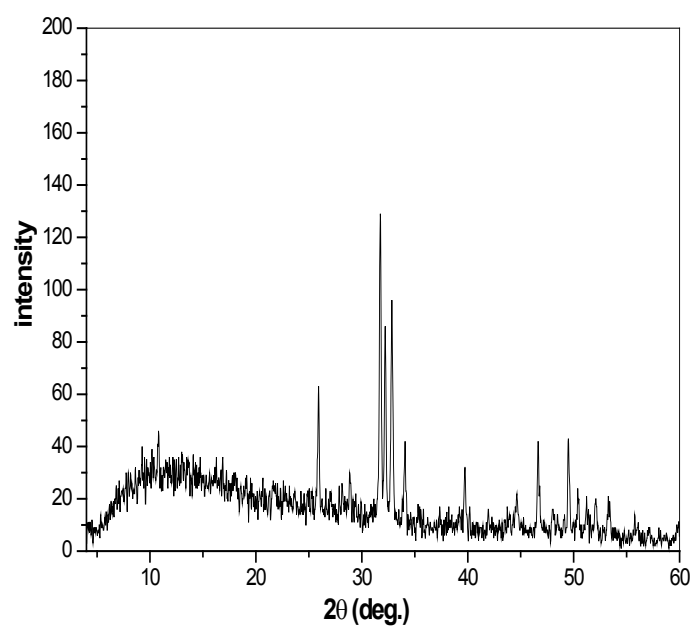

Fig. 2. X-ray of pure HAp.

J. Text. Color. Polym. Sci. 16, No. 2 (2019) 
TABLE1. XRD of pure HAp, $2 \theta$ values observed, $d_{2 \theta}$ with $d_{\text {refrences }}$ and $I_{\text {rel }}$ values.

\begin{tabular}{|c|c|c|c|c|c|}
\hline \multirow{2}{*}{ Seq., } & hkl & & & \\
& & & & \\
\end{tabular}

It can be concluded from the table 1 these $\left(d_{2 \theta}\right)$ $\left(\mathrm{I}_{\text {rel }}\right)$ for pure HAp are in full agreement with the corresponding values reported for hexagonal HAp of standard ICCD (file no, 01-073-6113) file and are assigned as crystalline HAp were obtained by this chemical precipitation method which shows the typical HAp patterns. The FTIR spectra of nano-HAp powder, prepared by wet precipitation method gave information on the chemical structure of HAp, presence of PVA and ceramic phase and chemical structure of composite HAp/PVA and HAp/PVA/MWCNT. The spectra are recorded in the range of $4000-400 \mathrm{~cm}^{-1}$ for all samples. The pattern shows the absorbance band at 1092.48 and $1051.98 \mathrm{~cm}^{-1}$ are due to the $\gamma_{3}$ vibrational mode of the phosphate group as it is the only band coming out in this part. The peak at $962.31 \mathrm{~cm}^{-1}$ is attributed to the $\gamma_{1}$ vibrational mode of the phosphate group as it is the only band coming out in this part which confirms the presence of crystallized HAp. The peak at $485.97 \mathrm{~cm}^{-1}$ is assigned to the $\gamma_{2}$ vibrational mode of the phosphate group. The peak at 603.61 and $570.83 \mathrm{~cm}-1$ correspond to $\gamma_{4}$ bending mode of the phosphate group [36]. The hydroxyl liberation mode found at $633.5 \mathrm{~cm}^{-1}$. The peaks at $1632.45 \mathrm{~cm}^{-1}$ represent the $\mathrm{OH}$ bending vibration of the absorbed water. The peak at $876.49 \mathrm{~cm}^{-1}$ , $1462.74 \mathrm{~cm}^{-1}$ Are due to the presence of a small amount of $\mathrm{CO}_{3}$ this is attributed to the trace impurities present in the starting material[37].

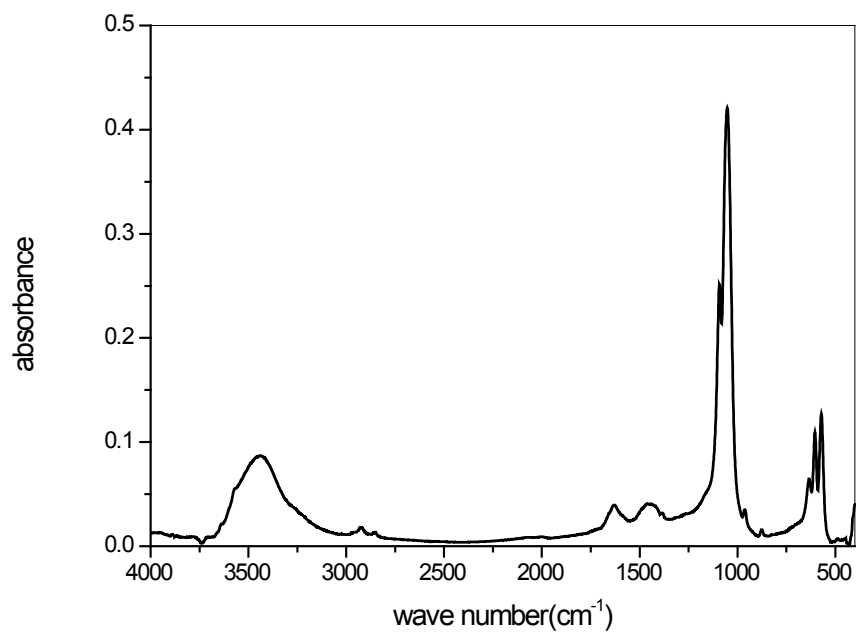

Fig. 3. FTIR of pure HAp. 
TEM images of pure porous n-HAp are demonstrated in Fig. 4. The TEM image showed that the particles exhibit spherical morphology. The particles size of pure porous HAp is about (4-20 nm). SEM has been used to estimate and examine porous HAp crystallite The microstructure of HAp particles is observed to be almost like a hexagonal with a mean crystallite size of about (4-20) $\mathrm{nm}$ in diameter as shown in fig 5a. EDX analysis of pure nano-HAp illustrate that the HAp particles had a $\mathrm{Ca} / \mathrm{P}$ ratio of 1.665 as show in fig. 6bthat very close to natural bone. Highly agglomerated hexagonal crystal plate like morphology was observed for synthesized HAp particles with crystallite size of (12.50) nm calculated from Scherer's equation.

\section{PVA/HAp and Porous HAp}

The diffraction pattern of the HAp/PVA composite polymer powder that were prepared by a blending process with different ratios of PVA $(5 \%$ 10\%-15\%-20\%). As show in Fig. 3a A comparison between the synthesized HAp and PVA/HAp show that the incorporation of HAp to PVA solution does not significantly affect the crystal structure of the lattice. The spectra of the samples are in full agreement with the corresponding values reported for hexagonal HAp of standard ICCD (file no, 01074-9780) file. It is well known that the PVA polymer exhibits a semi-crystalline structure with a large peak at a $2 \theta=19-20$ and a small peak at a $2 \theta=39-40[38-$ 42].It's worth mentioning that the characteristic peaks of PVA not found because the higher crystallinity of HAp and small volume fraction of PVA introduced into the composite. Peaks corresponding to HAp maintained their phase and crystallinity similar to pure HAp. Minor differences occur where intensity of XRD for the HAp/PVA composite reduced when the amount of added PVA increased. Porous HAp that formed after burning are in full agreement with the corresponding values reported for hexagonal HAp of standard ICCD (file no, 01-073-1731) file and are assigned as crystalline HAp which shows the same typical hydroxyapatite patterns as in pure HAp. Experimental results indicate that the 10\% PVA solution was found to impregnate the porous ceramics effectively to form HAp/PVA composite where PVA impregnation improved the compressive strength of porous nano-HAp ceramics.

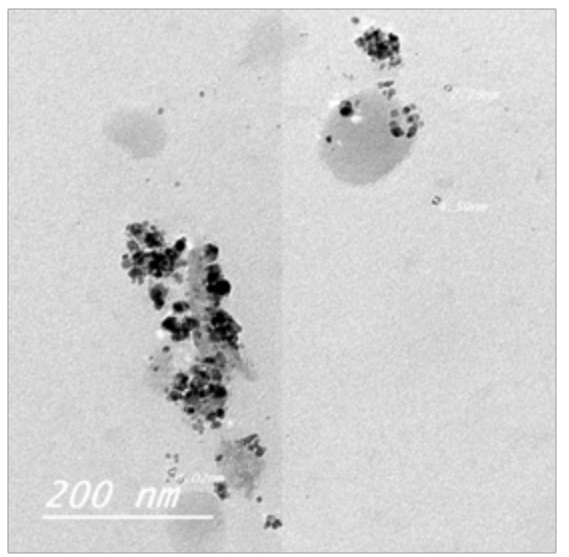

Fig. 4. TEM of pure HAp.

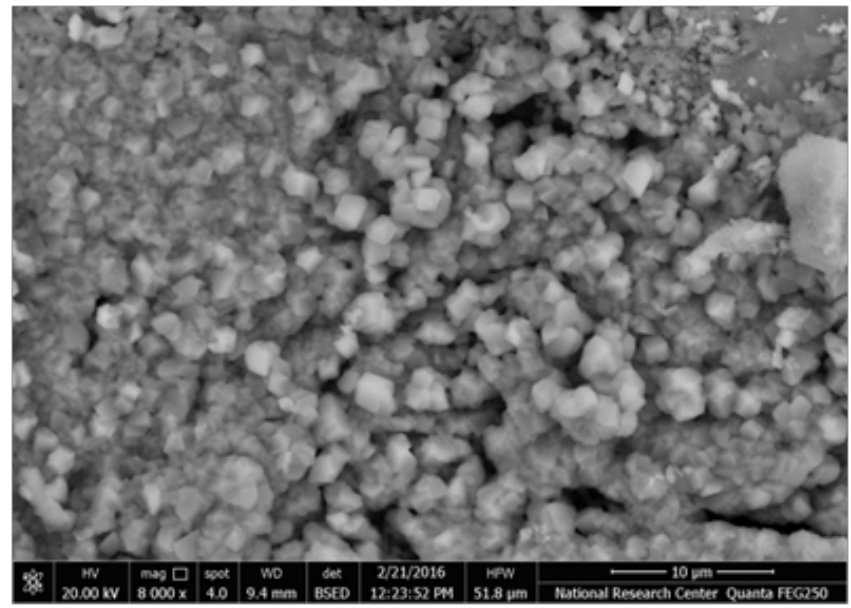

Fig. 5a. SEM for pure HAp. 


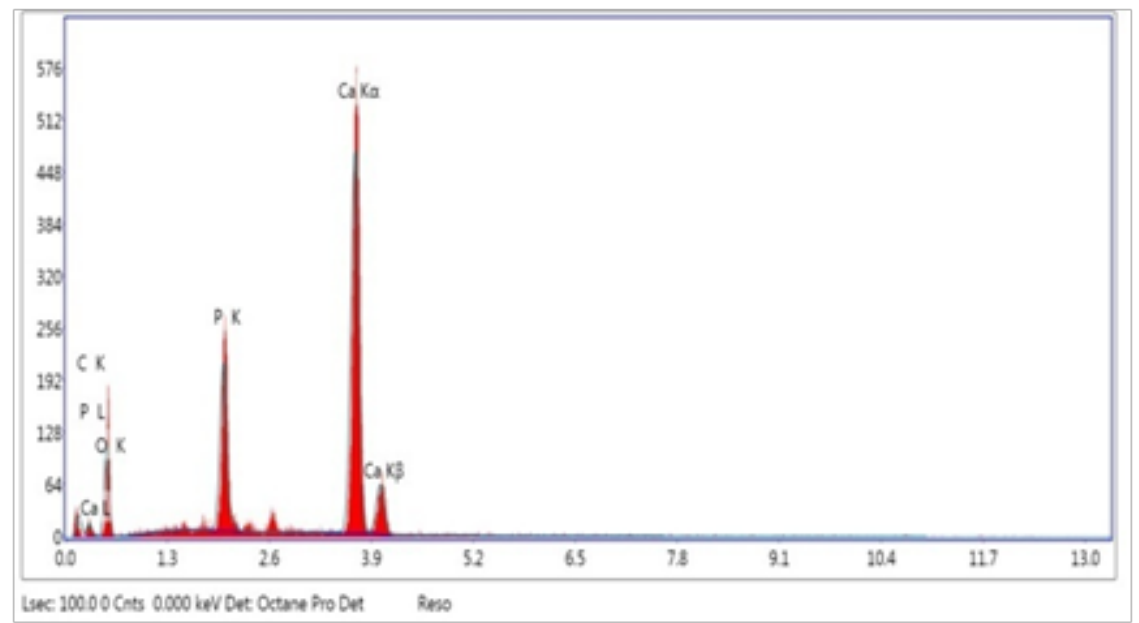

Fig. 5b. EDX analysis of pure HAp.

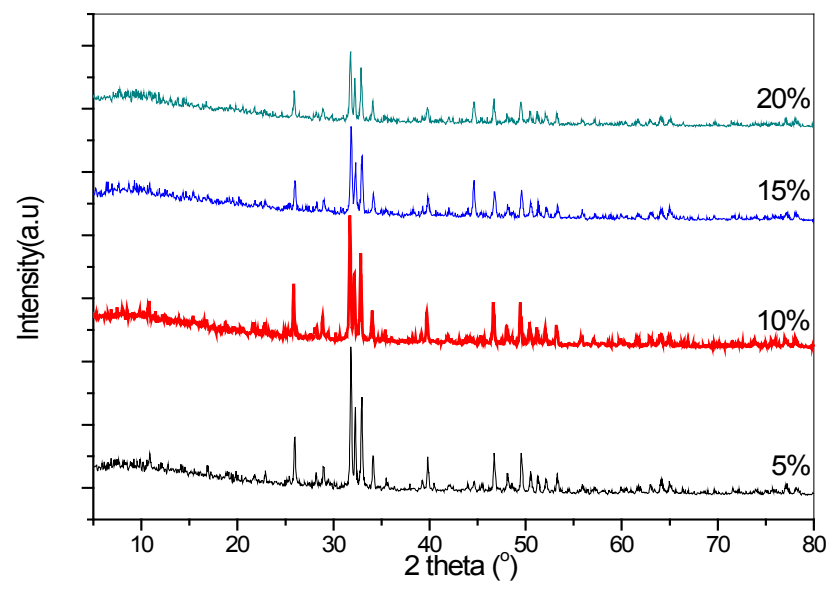

Fig.6a. XRD of HAp/PVA (5\%-10\%-15\%-20\%) before burning.

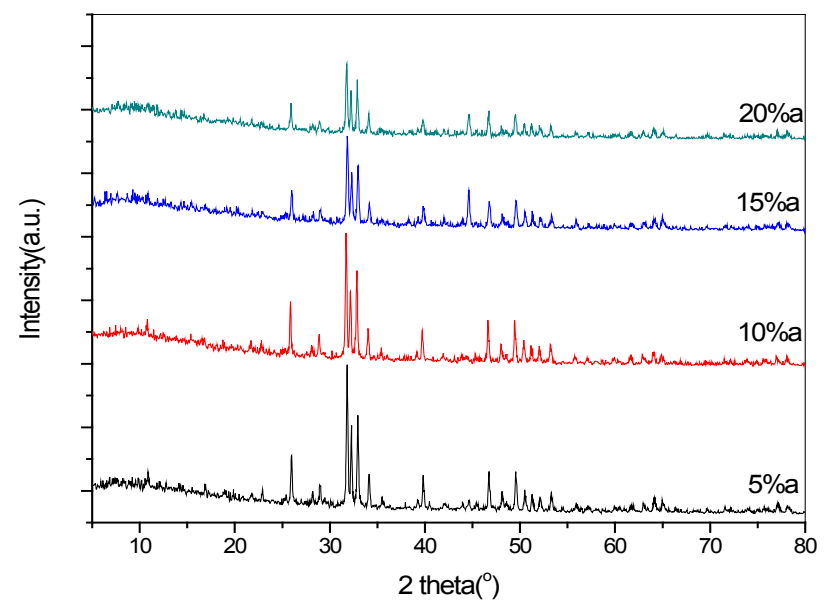

Fig. 6b. XRD HAp/PVA (5\%-10\%-15\%-20\%) after burning. 
The FTIR spectrum of HAp loaded PVA with different ratios of PVA $(5 \%-10 \%-15 \%$ $20 \%$ ) before burning is shown in figure $7 \mathrm{a}$. The characteristic structural band of both HAp and PVA were observed for all HAp/PVA samples before burn. The PVA spectra indicate wide intense band due to the presence of O-H hydroxyl group at $3438 \mathrm{~cm}^{-1}$. The peaks at $2925 \mathrm{~cm}^{-1}$ and $2856 \mathrm{~cm}^{-}$ ${ }^{1}$ represent $-\mathrm{CH}$ asymmetric and the symmetric stretching. The absorption band at $1103.08 \mathrm{~cm}^{-1}$ is represented $\mathrm{C}-\mathrm{O}$ stretching. The absorption beak at $1631 \mathrm{~cm}^{-1}$ is due to symmetric stretching of carboxylate anion (-COO-). The HAp spectra and HAp /PVA composite show a variable intensity of absorbance vary with PVA concentration in the sample in the adsorption range $3000-3500 \mathrm{~cm}^{-1}$. Strong and broadband at band $3440.38 \mathrm{~cm}^{-1}$ which characterize $\mathrm{O}-\mathrm{H}$ stretching frequency is well detected as a result of the increasing presence of HAp in composite materials. The PVA is shown by the absorption at $3438 \mathrm{~cm}^{-1}$ (OH stretch vibration), $2925 \mathrm{~cm}^{-1}$ (CH stretch vibration/ $\left.\mathrm{CH}_{2}\right), 1381 \mathrm{~cm}^{-1}$ (strain - $\mathrm{CH}$ vibration), $1047 \mathrm{~cm}^{-1}$ (vibration $-\mathrm{C}$ $\mathrm{C}-)$. In addition, the hydrogen bond on PVA ( $\mathrm{HOH}$ bond) was observed at $1631 \mathrm{~cm}^{-1}$. The two materials were interacted by a hydrogen bonding which is shown by the presence of the absorption peaks at $3000-3500 \mathrm{~cm}^{-1}$, an indication of a shift beak of the $-\mathrm{OH}$ of HAp and PVA. In the FTIR spectrum composite, the absorption peaks of each material are still observable but with a decrease in intensity and shifted from high frequency in pure HAp to low frequency. in HAP/PVA, as shown by the peak at $2859 \mathrm{~cm}^{-1}$ (vibration $-\mathrm{CH}$ ) shift to $2856 \mathrm{~cm}^{-1}$ the peak at $2927 \mathrm{~cm}^{-1}$ (bending vibration $-\mathrm{CH}_{2}$ ) shifted to2925 $\mathrm{cm}^{-1}$ [43]. The absorption peaks of $\mathrm{OH}$ stretch vibration still appear at $3438 \mathrm{~cm}^{-1}, 1631$ $\mathrm{cm}^{-1}$ (H-OH bending vibration), and at $1047 \mathrm{~cm}^{-}$ 1, $613 \mathrm{~cm}^{-1}$ and $568 \mathrm{~cm}^{-1}$ for the phosphate group. A broadening peak around $300-3500 \mathrm{~cm}^{-1}$ is due to the interaction between the constituent elements of the composite, such as hydrogen bonding between PVA and HAp. The $-\mathrm{OH}$ bind with the $-\mathrm{OH}$ group of HAp that agree with literature[44, 45]. In reference to the FT-IR analysis we notice that the HAp loaded with $10 \%$ PVA is more convenient to produce porous HAp. The FTIR spectrum of HAp loaded PVA after burn shown in Fig.; (7b) indicated that the peaks in all samples matched well with the standard pure HAp pattern.

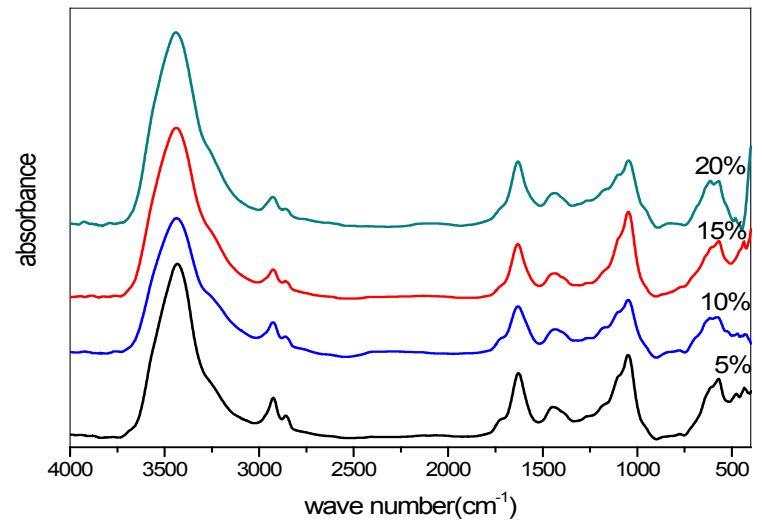

Fig. 7a. FTIR of HAp/PVA (5\%-10\%-15\%-20\%) before burning.

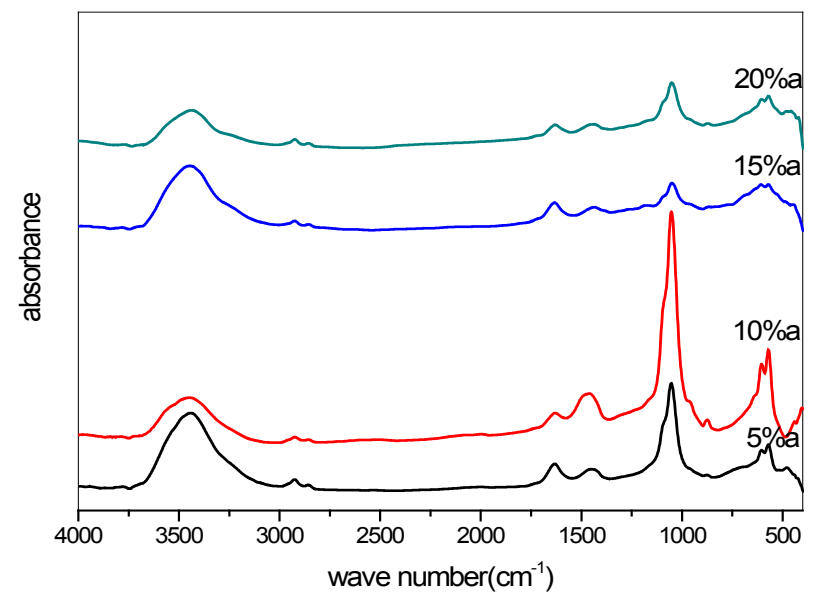

Fig. 7b. FTIR of HAP/PVA (5\%-10\%-15\%-20\%) after burning. 


\section{SEM analysis of porous HAp}

In case of composites, when the composition of PVA is added to HAp and burned to form porous HAp showed in fig 8a-8d, the SEM showed agglomerated spherical crystal and the hexagonal shape starts to disappear. Closed pores in the HAp crystals were also seen. The increase in the PVA compositions i.e., $5 \% .10 \% .15 \% .20 \%$ leads to a corresponding change of surface morphology to an irregular morphology. In addition, it is clear that the particle size decreases with increase in PVA composition. The particles size values are listed in Table 2.

\section{Porous HAp reinforced MWCNTS}

Fig. (9b) shows the diffraction pattern of the HAp/10\%PVA/MWCNT composite powder that

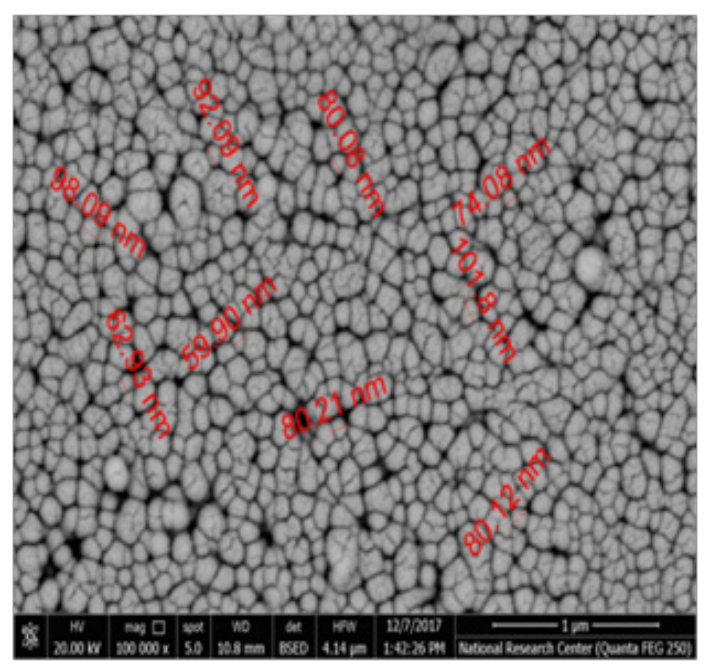

Fig. 8a. SEM (PVA 5\% / HAp) after burning.

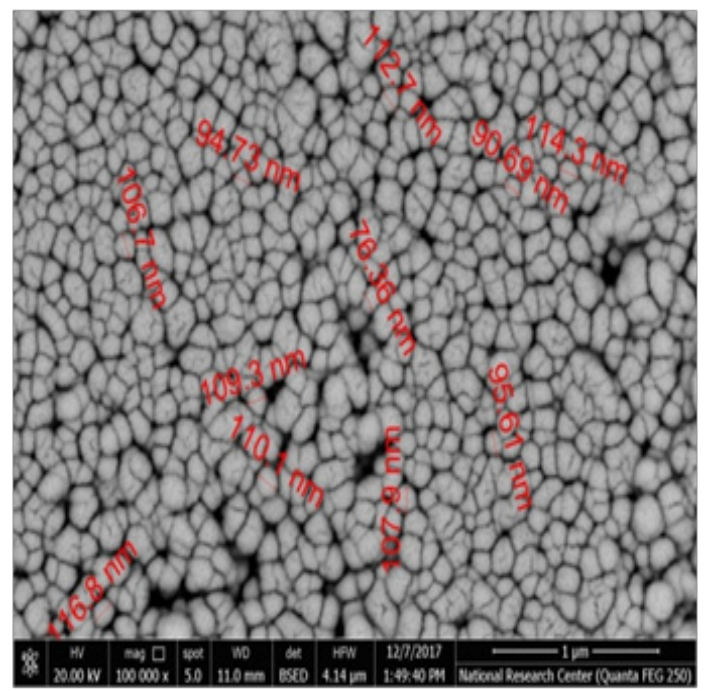

Fig. 8c. SEM (HAp/ PVA 15\%) after burning.

J. Text. Color. Polym. Sci. 16, No. 2 (2019) was prepared by a blending process with different concentration of MWCNT (0.0005-0.001-0.002$0.003) \mathrm{gm}$. All the crystalline peaks of composites (HAp/PVA/MWCNT) before burning are confirmed by the corresponding values reported for hexagonal HAp of standard ICCD (file no, 01073-0293) file for stoichiometric HAp and HAp composite with PVA/MWCNT with different concentration of MWCNTs after burning are in full agreement with the corresponding values reported for hexagonal HAp of standard ICCD (file no, 01-074-9780) file and standard ICCD (file no, 01-071-5049) file and are assigned as crystalline HAp were obtained by blending process which show the same typical hydroxyapatite patterns as in pure HAp. All crystalline phases, whether

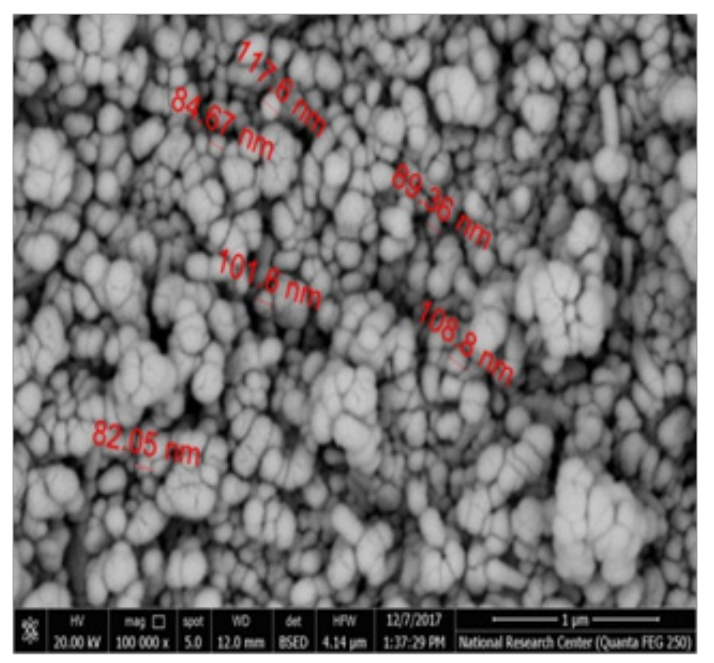

Fig. 8b. SEM (PVA 10\%/ HAp) after burning.

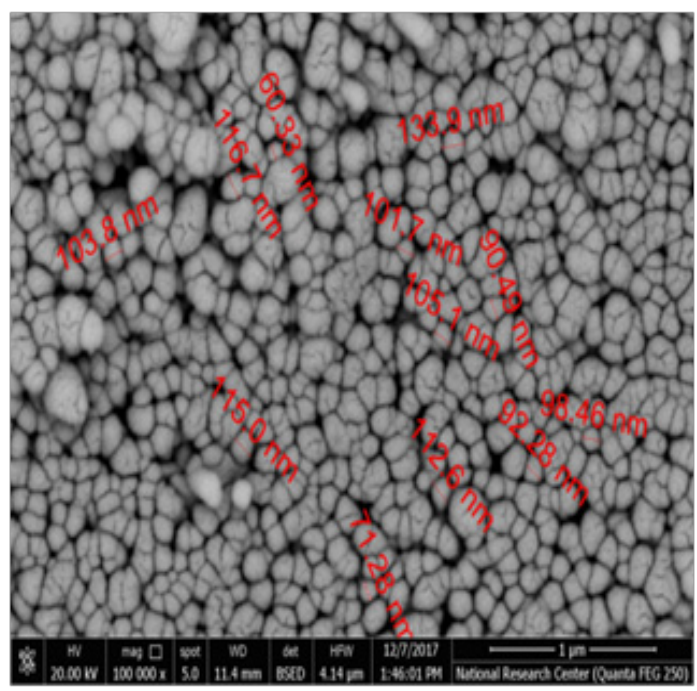

Fig. 8d. SEM (HAp/ PVA 20\%) after burning. 
before or after burning are conformed by ICCD files as shown pervious except a small peak (002) at $2 \theta$ of $25.97^{\circ}$ for carbon. This indicates the existence of the MWCNTs. Most conducted studies have not been able to support the presence of carbon phases by XRD analysis. This is due to the low concentration of MWCNTs in the ceramic matrix composite as well as the correspondence of the main peak of carbon and HAp at $2 \theta$ of $26^{\circ}$. Withal, the composite preparation was difficult to notice within the sensitivity limit of the tool[46]. The formation of HAp- PVA-MWCNT nano blends were further confirmed by analyzing the FTIR spectra. From the Table (2) The apparent average crystallite size determined from the XRD pattern by Scherrer's equation suggested that broadening is produced by particle size and potential contributions from strain was ignored [47]. Since the most intense peak in the HAp diffraction pattern at 31.7 , the relative intensity of the diffraction at the same Bragg angle (31.7 $)$ matches with the relative presence of HAp phase in the blend. The particle size is determined by the Scherrer equation [31].

$t=(0.96 \times \lambda) /(\beta \times \cos \theta)$, where

$\mathrm{t}=$ particle size, $\lambda=$ wavelength of $\mathrm{K} \alpha-\mathrm{Cu}$ used $=1.54 \AA$

$\beta=$ Full Width Half Maximum (FWHM) in terms of radians.

$\Theta=$ Bragg angle of peak from diffraction.

Specific surface area of the HAp is determined by the formula

$\mathrm{S}=6 \times 10^{3} / \mathrm{d} \times \mathrm{t}$.

where $t$ is the crystallite size (nm) and d-is the theoretical density of HAp $\left(3.16 \mathrm{~g} / \mathrm{cm}^{3}\right)$.The results suggested that in case of (HAp/PVA) blend the apparent average crystal size is the same by increasing the percentage of the PVA before and after burning.as shown in fig.7a-7bIn case of the presence of MWCNTs the outcomes indicated that the apparent average crystal size increased by increasing the share of the MWCNT beforeburning.as shown in fig.9aBut the opposite occurred after burning as shown in fig $9 \mathrm{~b}$ where the crystallite size of the HAp/.0003 MWCNT are significantly smaller, with average grain size of $85 \pm 29 \mathrm{~nm}$ (tab.2). This decrease of the crystallite size can be linked to the presence of carbon nanotubes on the grain boundaries during grain growth[27].

TABLE 2. Line width, crystalline size and specific surface area.

\begin{tabular}{|c|c|c|c|c|c|}
\hline Sample & & $2 \theta\left({ }^{\circ}\right)$ & $\begin{array}{l}\text { FWHM } \\
\text { (rad) }\end{array}$ & $\begin{array}{l}\text { Crystal } \\
\operatorname{size}(n m)\end{array}$ & $\begin{array}{l}\text { Specific surface } \\
\operatorname{areas}\left(\mathrm{m}^{2} / \mathrm{g}\right)\end{array}$ \\
\hline Pure HAp & & $31.7^{\circ}$ & 0.0123 & 12.50 & 151.90 \\
\hline \multirow{4}{*}{ HAp/PVA before burning } & $5 \%$ & $31.8^{\circ}$ & 0.00134 & 114.7 & 16.55 \\
\hline & $10 \%$ & $31.7^{\circ}$ & 0.00134 & 114.7 & 16.55 \\
\hline & $15 \%$ & $31.8^{\circ}$ & 0.00134 & 114.7 & 16.55 \\
\hline & $20 \%$ & $31.7^{\circ}$ & .0 .001787 & 86 & 22.08 \\
\hline \multirow{4}{*}{ HAp/PVA after burning } & $5 \%$ & $31.6^{\circ}$ & 0.00134 & 114.7 & 16.55 \\
\hline & $10 \%$ & $31.6^{\circ}$ & 0.00134 & 114.7 & 16.55 \\
\hline & $15 \%$ & $31.5^{\circ}$ & 0.00134 & 114.7 & 16.55 \\
\hline & $20 \%$ & $31.6^{\circ}$ & 0.001787 & 85.96 & 22.09 \\
\hline \multirow{4}{*}{$\begin{array}{l}\text { H A p / P VA - M W C N Ts } \\
\text { before burning }\end{array}$} & 0.0005 & $31.8^{\circ}$ & 0.00134 & 114.7 & 16.55 \\
\hline & 0.001 & $31.7^{\circ}$ & 0.00134 & 114.7 & 16.55 \\
\hline & 0.002 & $31.6^{\circ}$ & 0.00134 & 114.7 & 16.55 \\
\hline & 0.003 & $31.7^{\circ}$ & 0.00089 & 172.7 & 10.99 \\
\hline \multirow{4}{*}{$\begin{array}{l}\text { HAp/PVA-MWCNTs after } \\
\text { burning }\end{array}$} & 0.0005 & $31.8^{\circ}$ & 0.00134 & 114.7 & 16.55 \\
\hline & 0.001 & $31.7^{\circ}$ & 00.00134 & 114.7 & 16.55 \\
\hline & 0.002 & $31.6^{\circ}$ & 0.00134 & 114.7 & 16.55 \\
\hline & 0.003 & $31.6^{\circ}$ & 0.001787 & 85.98 & 22.08 \\
\hline
\end{tabular}




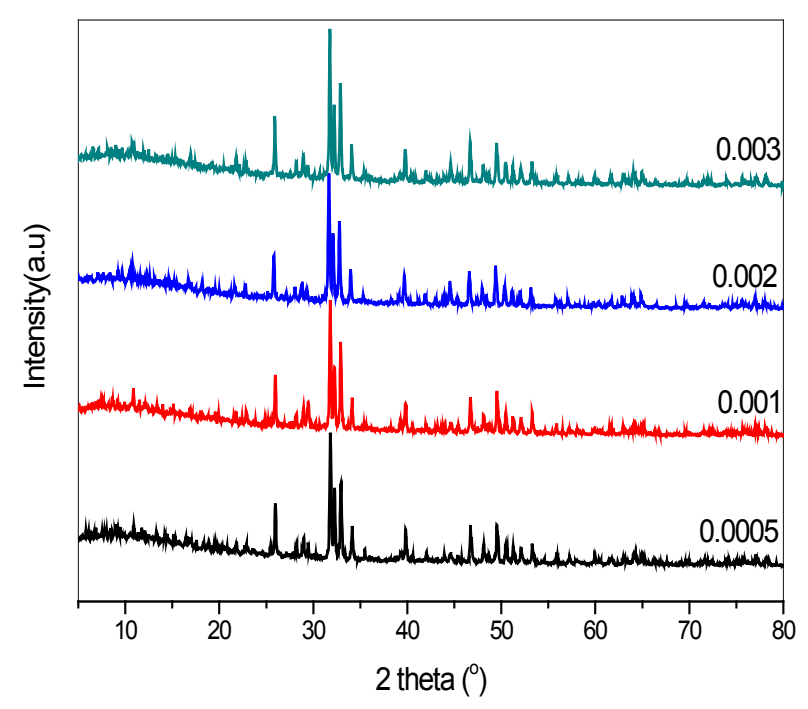

Fig. 9a. XRD HAp/10\%PVA/MWCNT (0.0005-0.001-0.002-0.003) before burning.

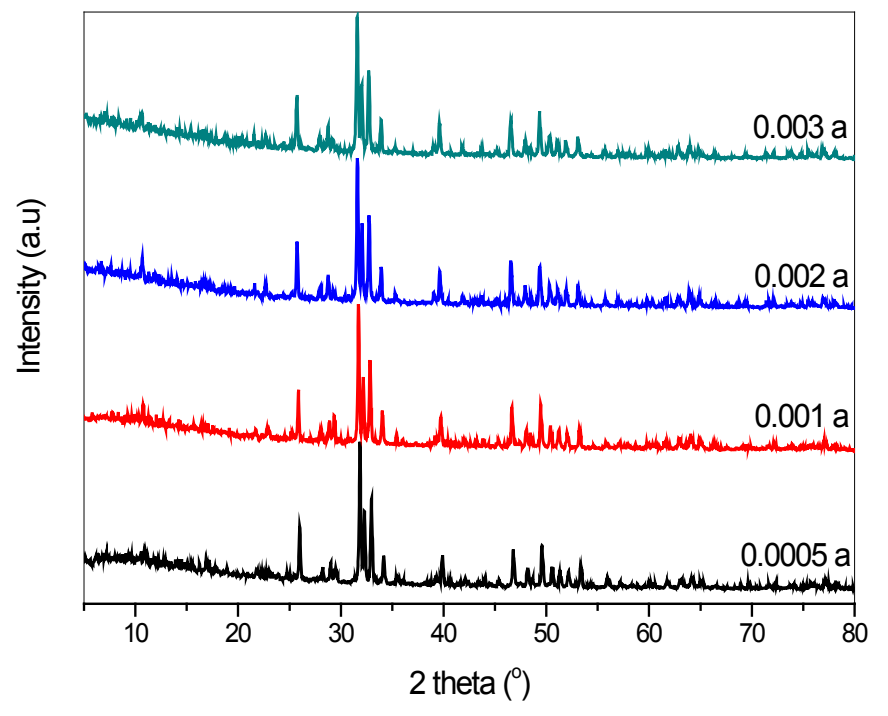

Fig. 9b. XRD of HAP/10\%PVA/MWCNT (0.0005-0.001-0.002-0.003)after burning.

The FTIR analysis showed in Figure (10a) HAp/10\%PVA/MWCNTs $(0.0005,0.001,0.002$, and 0.003$) \mathrm{gm}$ powders before burning. The $\mathrm{OH}$ stretching bands are detected at $3432 \mathrm{~cm}^{-1}$. The phosphate bands were identified at 1040 and 569 $\mathrm{cm}^{-1}$. Their presence confirms the formation of a well-crystallized hydroxyapatite structure. The spectrum also showed the stretching modes of carbonate ions and hydroxyl groups which implied the presence of MWCNTs on the HAp. The absorption bands observed in the range of 1300$1650 \mathrm{~cm}^{-1}$ are due to the stretching and bending modes of $\mathrm{C}-\mathrm{O}$ and $\mathrm{P}-\mathrm{O}$ bands and air carbonate J. Text. Color. Polym. Sci. 16, No. 2 (2019)
$(\mathrm{CO} 3)^{-2}$ ions, which appear sharper when the MWCNTs increase because of high surface area of the MWCNTs. The distinct shoulder at 874 with an increase in MWCNTs indicates the presence of $\mathrm{HPO}_{4}^{-2}$ in the structure, and bands around $2924 \mathrm{~cm}^{-1}$ and $2854 \mathrm{~cm}^{-1}$ are due to the asymmetric and symmetric stretching of $\mathrm{C}-\mathrm{H}$ band. The carbonate band was also observed at $1631 \mathrm{~cm}$ 1. By comparing the two spectra (pure HAp and HAp/10\%PVA/MWCNTs) before burning in the region of $3000-4000 \mathrm{~cm}^{-1}$, broadening and shifting of the bands became evident. In the HAp sample, this indicated low crystallinity grade compared to 
the HAp/MWCNTs composite samples. It might also confirm the positive effect of nanotubes on improving the quality of hydroxyapatite crystallization[48]. By comparing the spectra (HAp/10\% PVA/MWCNTs) with different concentration of MWCNTs powders after burning as shown in fig10b the absorption peaks of each material are still observable but with a decrease in intensity, when the concentration of MWCNTs increase. The peak from both composite in all samples matched well with synthesized pure HAp pattern.

The SEM morphology of HAp/PVA/MWCNTs composites before burning is shown in Fig.11a11d. which show agglomerated HAp with PVA/ MWCNTs imbedded in ceramic matrix of HAp.
While Fig. 12a-12b revealed that porous HAp/ MWCNTs after burning exhibit porous nature of the nanocomposites which very favorable for cellular growth with presence of fine hair MWCNTs chains attached to the HAp grains. MWCNTs chains are distributed in the ceramic matrix with good uniformity. The lattice of HAp with MWCNTs remained mixed together. Closed pores in the HAp crystals were also It is quite interesting to note that, in the case of composites HAp/MWCNTs after burning the specific surface area increased with increasing weight of MWCNTS as shown in table 2 It proves that MWCNTs have been successfully introduced into porous HAp matrix and, in addition, that the MWCNTs might still possess their excellent mechanical properties.

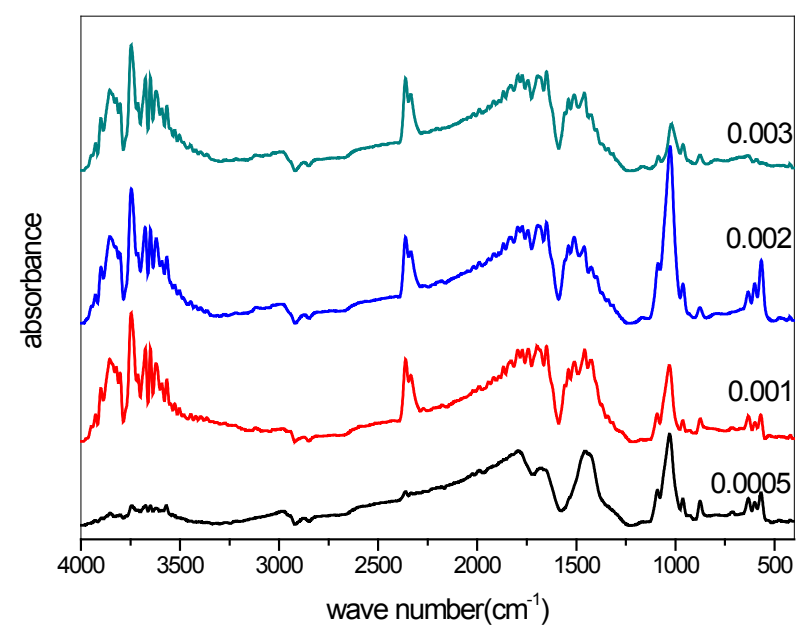

Fig. 10a. FTIR of HAP/10\%PVA/MWCNTs (0.0005-0.001-0.002-0.003) gm before burning.

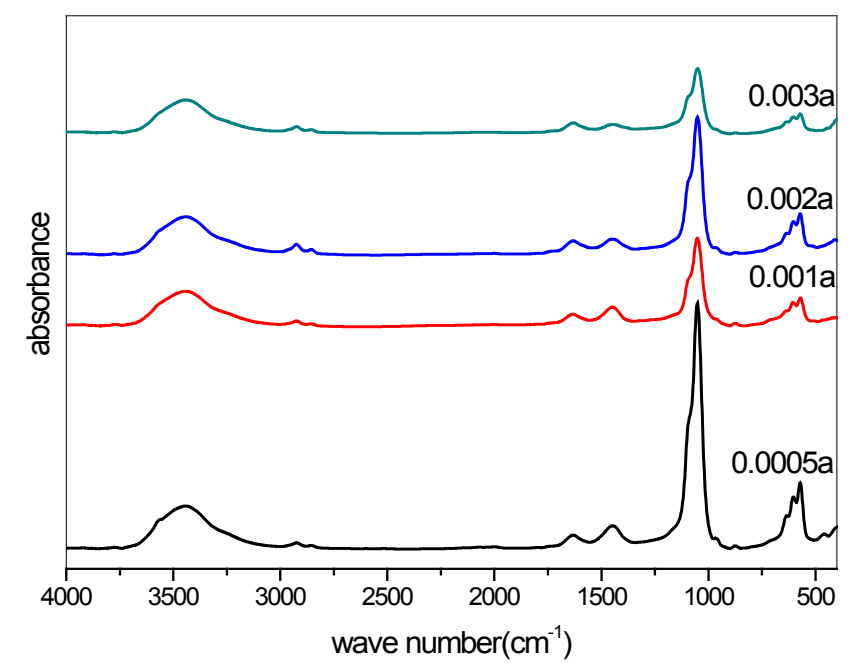

Fig. 10b. FTIR of HAP/10\%PVA/MWCNT (0.0005-0.001-0.002-0.003) gm after burning. 


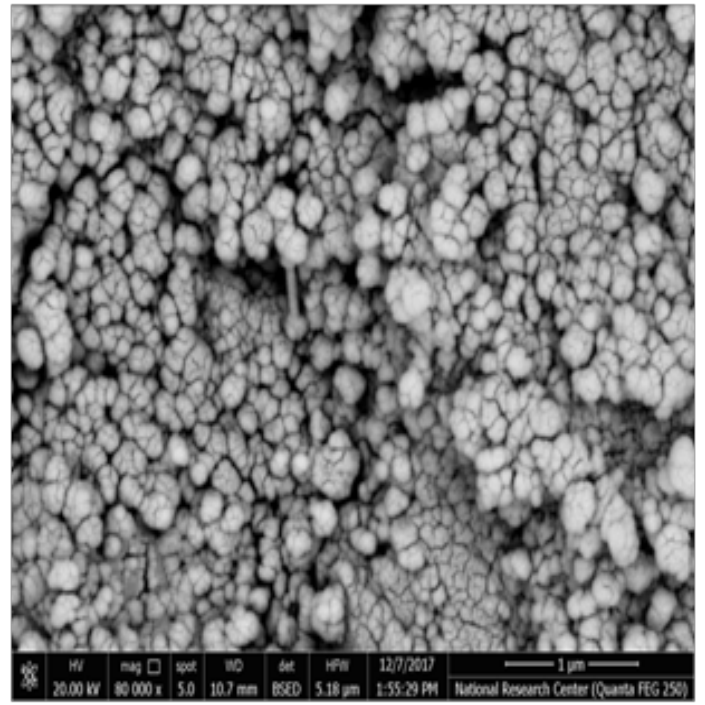

Fig. 11a. SEM (HAp /10\% PVA/ 0.0005MWCNT) before burning.

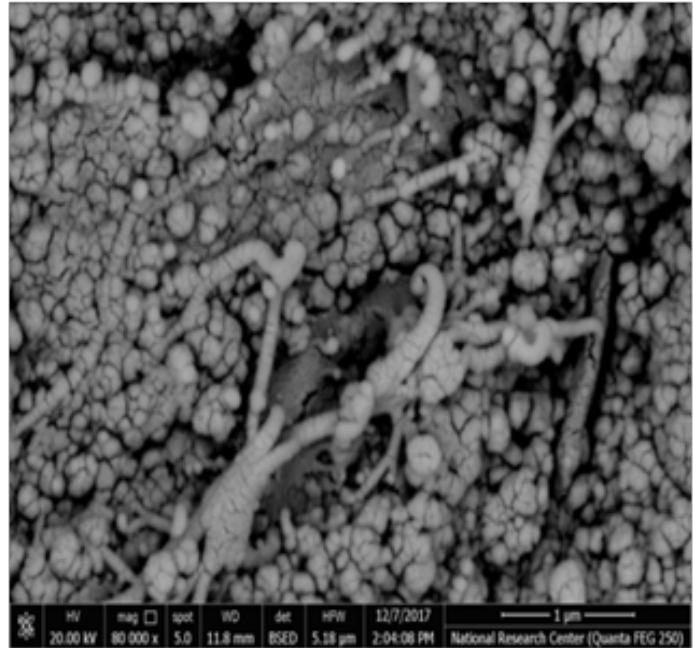

Fig. 11c. SEM (HAp $/ 10 \%$ PVA/ 0.0025MWCNT) before burning.

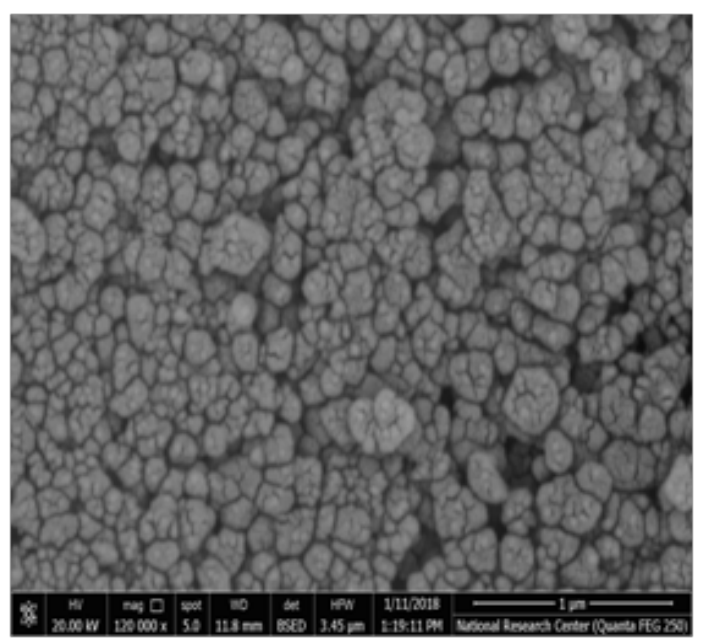

Fig. 12a. SEM (HAp /10\% PVA/ 0.0005MWCNT) after burning.

J. Text. Color. Polym. Sci. 16, No. 2 (2019)

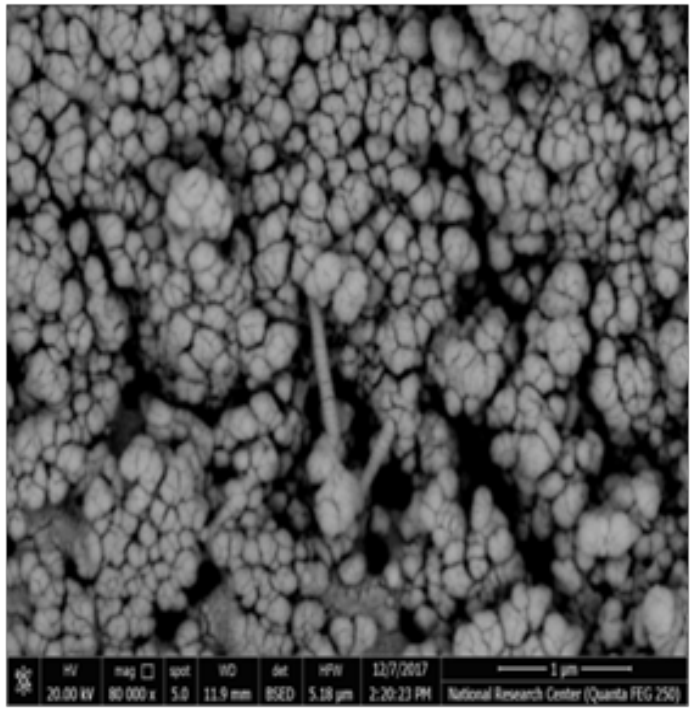

Fig. 11b. SEM (HAp /10\% PVA/ 0.001MWCNT) before burning.

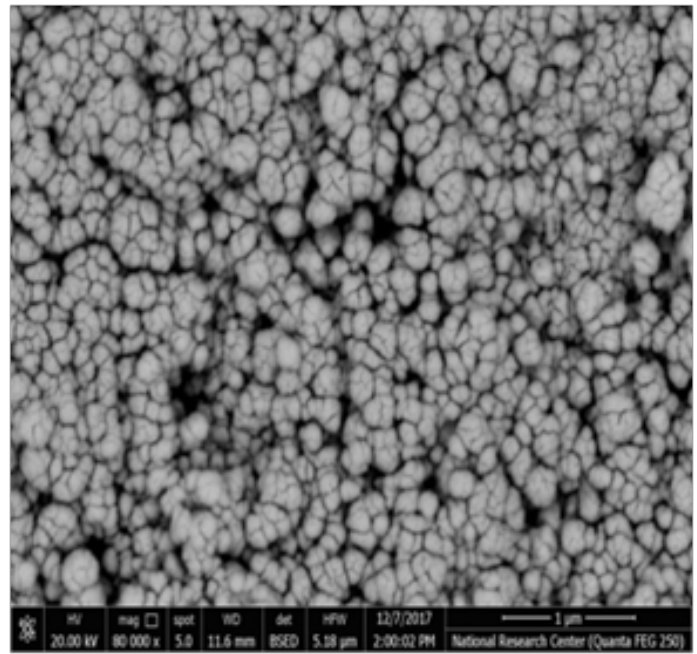

Fig. 11d. SEM (HAp $/ 10 \%$ PVA/ 0.003MWCNT) before burning.

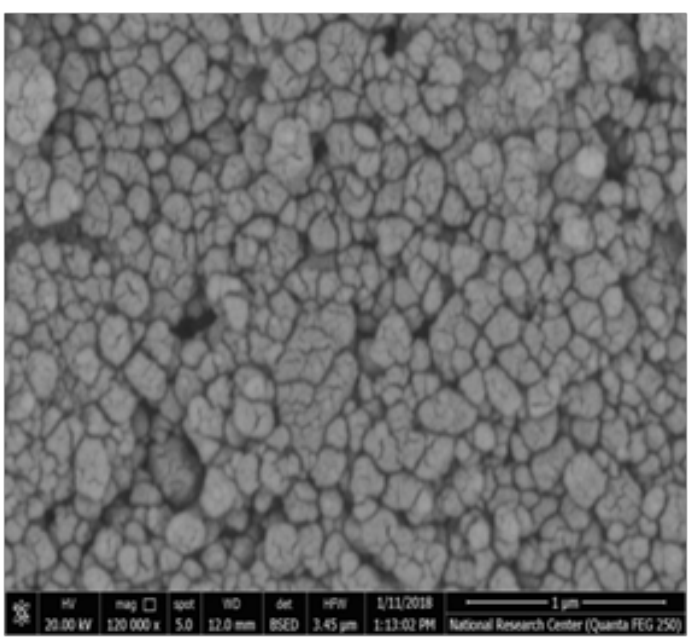

Fig. 12b. SEM (HAp /10\% PVA/ 0.001MWCNT) after burning. 


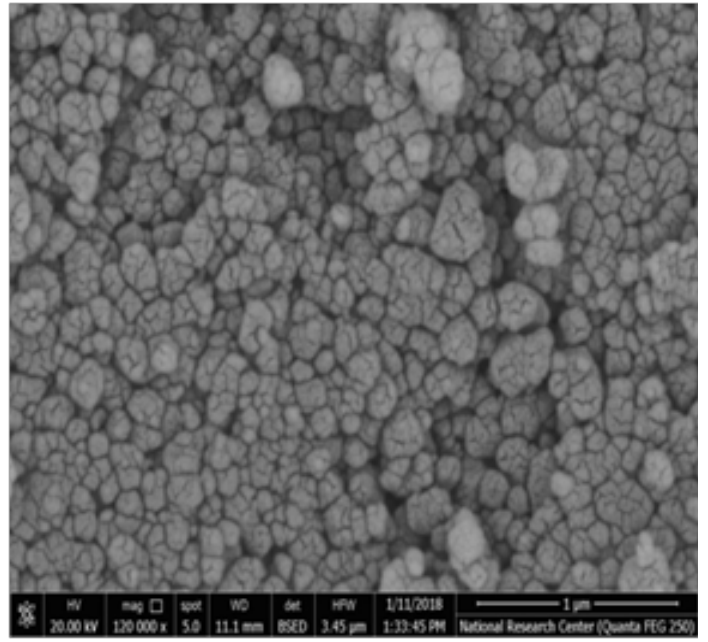

Fig. 12c. SEM (HAp /10\% PVA/ 0.002MWCNT) after burning.

\section{Mechanical test}

The stress-strain test was studied to the best ratio for between HAp and PVA for porous scaffold construction. The effect of MWCNTs on the mechanical properties of porous scaffold was studied for different loaded ratios of MWCNTs. Figure (13) describe the stress-strain curve for HAp/PVA porous composites after burn. As shown in the figure mechanical properties were enhanced in the polymer ratio $10 \%$ than the other composites. The compressive strength and elastic modulus were calculated and listed in Table (3). The mechanical parameters appear to increase in $10 \%$. This may attributed to the higher crystalline phase of HA with better particles distribution within the matrix result in formation of adequate pore size after burn. These results are agreed

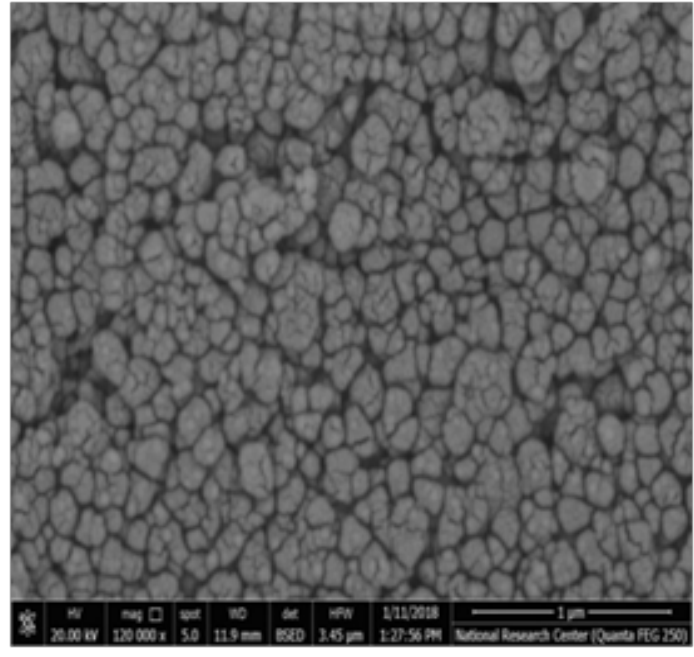

Fig.12d. SEM (HAp /10\% PVA/ 0.003MWCNT) after burning.

with XRD and FTIR analysis. Then the 10\% sample was choose for addition the MWCNTs. The incorporation of MWCNTs within the HAp during preparation increases the mechanical parameters of porous HAp. Figure (14) show the stress-strain curve for HAp reinforced with MWCNTs with different ratios. The compressive strength and elastic modulus were calculated as in table (3). From the figure and table it is cleared that the compressive strength and elastic modulus were increased as the ratio of MWCNTs increased this may be attributed to the good reinforcement of the MWCNTs when incorporated with HAp[49].From the above, we conclude that the addition of MWCNTs improve the physical and mechanical properties of porous HAp make it a good candidate for use in medical applications.

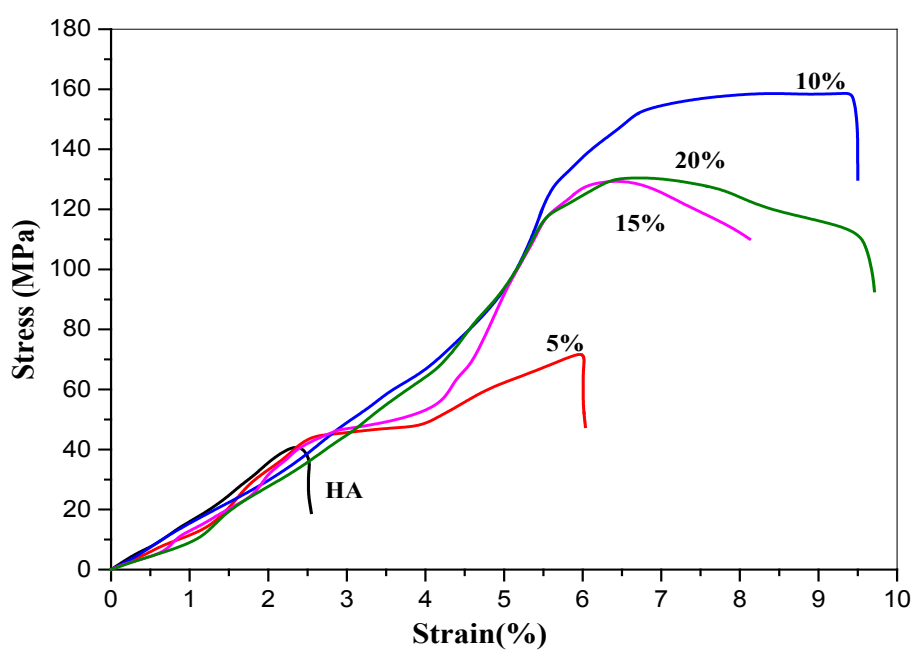

Fig. 13. Stress-Strain test for pure HAp and HAP/PVA biocomposites after burning. 


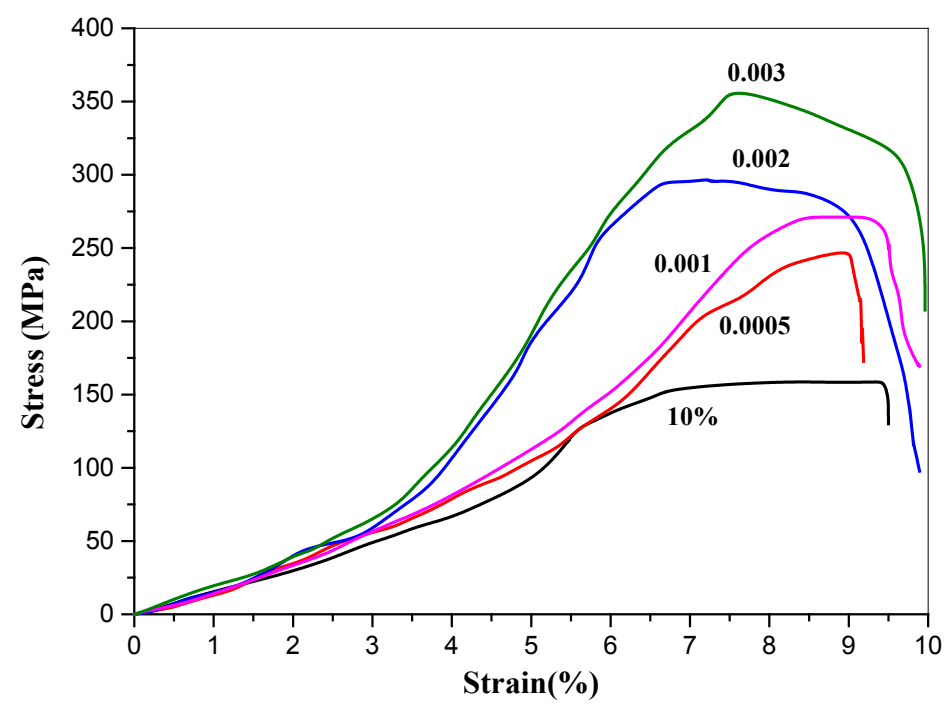

Fig. 14. Stress-Strain test for HAp/PVA-MWCNTs biocomposites after burning.

TABLE 3. Compressive strength, Elastic modulus for pure HAp, HAp/PVA and HAp/PVA-MWCNTs biocomposites.

\begin{tabular}{lccc}
\hline \multicolumn{2}{l}{ Sample } & Elastic Modulus (GPa) & compressive strength ( \\
\hline Pure HAp & & \\
\hline & $5 \%$ & $1.63 \pm 0.072$ & $42.77 \pm 1.57$ \\
& $10 \%$ & $1.10 \pm 0.052$ & $71.82 \pm 2.23$ \\
HAp/PVA & $1.72 \pm 0.057$ & $150.82 \pm 2.88$ \\
& $15 \%$ & $1.27 \pm 0.073$ & $130.00 \pm 3.31$ \\
& $20 \%$ & $1.56 \pm 0.064$ & $130.02 \pm 1.11$ \\
& & $2.61 \pm 0.016$ & $248.07 \pm 3.65$ \\
& 0.0005 & $2.75 \pm 0.012$ & $271.15 \pm 4.33$ \\
HAp/PVA-MWCNTs & 0.001 & $3.84 \pm 0.022$ & $296.86 \pm 3.75$ \\
& 0.002 & $4.64 \pm 0.062$ & $355.76 \pm 2.77$ \\
& 0.003 & &
\end{tabular}

\section{Conclusion}

Porous HAp was prepared using PVA with different concentrations to control pore size distribution. X-ray diffraction studies showed the formation of HAp and the spectrum matched with the standard ICCD values. The FTIR charts depict that the synthesized powder is certainly HAp, the bonding between HAp and PVA appeared in spectra and spectra of HAp loaded with MWCNTs confirm the positive effect of MWCNTs on improving the quality of HAp crystallization and mechanical properties. The raw HAp powder was calcined at $900 \mathrm{C}$ for four hours. Showed increase in crystalline phases. The FTIR analysis of the PVA/HAp composites showed that both of the components existed in the composite. The SEM J. Text. Color. Polym. Sci. 16, No. 2 (2019) images showed that the composites [50] have a homogeneous and porous microstructure with pore sizes about $100-200 \mu$. Hydroxyapatite particles were dispersed uniformly and were embedded in the PVA of $10 \%$ concentration and made enhancement of biocomposite as a result of adding MWCNTs matrix that shown in previous pattern.

\section{References}

1. Torricelli, P., Aldini, N.N., and Fini, M., Biological assessment of bioceramics, in Advances in Ceramic Biomaterials., Elsevier. p. 111-125 (2017).

2. Baino, F., Novajra, G., and Vitale-Brovarone, C., Bioceramics and scaffolds: a winning combination for tissue engineering.Frontiers in bioengineering and biotechnology. 3, p. 202. (2015). 
3. Biswal, S., Preparation of Hydroxyapatite Porous Scaffold. (2010).

4. Mohammad, N.F., Othman, R., and Yee-Yeoh, F., Nanoporous hydroxyapatite preparation methods for drug delivery applications.Rev. Adv. Mater. Sci. 38, p. 138-147. (2014).

5. LeGeros, R.Z., Daculsi, G., and LeGeros, J.P., Bioactive bioceramics, in Musculoskeletal Tissue Regeneration. Springer. p. 153-181 (2008).

6. Navarro, M., Michiardi, A., Castano, O., and Planell, J., Biomaterials in orthopaedics.Journal of the royal society interface. 5(27), p. 1137-1158. (2008).

7. Dorozhkin, S.V., Bioceramics of calcium orthophosphates.Biomaterials. 31(7), p. 1465-1485. (2010).

8. Mohammad, N.F., Othman, R., and Yeoh, F., Nanoporous hydroxyapatite preparation methods for drug delivery applications. Rev. Adv. Mater. Sci. 38, p. 138-214. (2014).

9. Yoshikawa, H. and Myoui, A., Bone tissue engineering with porous hydroxyapatite ceramics.Journal of Artificial Organs. 8(3), p. 131-136. (2005).

10. Cyster, L., Grant, D., Howdle, S., Rose, F., Irvine, D., Freeman, D., Scotchford, C., and Shakesheff, K., The influence of dispersant concentration on the pore morphology of hydroxyapatite ceramics for bone tissue engineering.Biomaterials. 26(7), p. 697-702. (2005).

11. Lahiri, D., Ghosh, S., and Agarwal, A., Carbon nanotube reinforced hydroxyapatite composite for orthopedic application: a review.Materials Science and Engineering: C. 32(7), p. 1727-1758. (2012).

12. Yoruç, A. and Koca, Y., Double step stirring: a novel method for precipitation of nano-sized hydroxyapatite powder.Digest Journal of Nanomaterials \& Biostructures (DJNB). 4(1), p. (2009).

13. Hare, G., Ravi, B., and Chaim, R., Effects of solvent and agitation on microstructural characteristics of sol-gel derived nanocrystalline Y-TZP powders. Materials Letters. 39(1), p. 63-68. (1999).

14. Pataquiva-Mateus, A., Ferraz, M., and Monteiro, F., Nanoparticles of hydroxyapatite: preparation, characterization and cellular approach-an overview. Revista Mutis. 3(2), p. 43-57. (2013).

15. Salariana, M., Solati-Hashjin, M., Goudarzi, A., Shafiei, S.S., Salarian, R., and Nemati, Z.A., Effect of Surfactant in Formation of Hydroxyapatite Nano-Rods under Hydrothermal Conditions.Ira- nian Journal of Pharmaceutical Sciences. 4(2), p. 157-162. (2008).

16. Sun, Y., Guo, G., Wang, Z., and Guo, H., Synthesis of single-crystal HAP nanorods. Ceramics International. 32(8), p. 951-954. (2006).

17. Hench, L.L., Bioceramics: from concept to clinic. Journal of the american ceramic society. 74(7), p. 1487-1510. (1991).

18. Hench, L.L., Biomaterials: a forecast for the future. Biomaterials. 19(16), p. 1419-1423. (1998).

19. Saiz, E., Gremillard, L., Menendez, G., Miranda, P., Gryn, K., and Tomsia, A.P., Preparation of porous hydroxyapatite scaffolds.Materials Science and Engineering: C. 27(3), p. 546-550. (2007).

20. Pattanayak, D.K., Divya, P., Upadhyay, S., Prasad, R., Rao, B., and Mohan, T.R., Synthesis and evaluation of hydroxyapatite ceramics. Trends Biomater Artif Organs. 18(2), p. 87-92. (2005).

21. Park, J.B., Lakes, Biomaterials: An Introduction. Plenum Press, New York. p. (1992).

22. Kamal, H. and Hezma, A., Structure and Physical Properties of Borosilicate as Potential Bioactive Glasses.Silicon. p. 1-8. (2017).

23. Riman, R.E., Suchanek, W.L., Byrappa, K., Chen, C.-W., Shuk, P., and Oakes, C.S., Solution synthesis of hydroxyapatite designer particulates.Solid State Ionics. 151(1-4), p. 393-402. (2002).

24. Agrawal, K., Singh, G., Puri, D., and Prakash, S., Synthesis and characterization of hydroxyapatite powder by sol-gel method for biomedical application.Journal of Minerals and Materials Characterization and Engineering. 10(08), p. 727. (2011).

25. Tsui, Y., Doyle, C., and Clyne, T., Plasma sprayed hydroxyapatite coatings on titanium substrates Part 1: Mechanical properties and residual stress levels. Biomaterials. 19(22), p. 2015-2029. (1998).

26. Yıldırım, O., Preparation and characterization of chitosan/calcium phosphate based composite biomaterials. İzmir Institute of Technology (2004).

27. Veljović, Đ., Vuković, G., Steins, I., Palcevskis, E., Uskoković, P., Petrović, R., and Janaćković, Đ., Improvement of the mechanical properties of spark plasma sintered hap bioceramics by decreasing the grain size and by adding multi-walled carbon nanotubes.Science of Sintering. 45(2), p. 233-243. (2013).

28. Wong, E.W., Sheehan, P.E., and Lieber, C.M., Nanobeam mechanics: elasticity, strength, and toughness J. Text. Color. Polym. Sci. 16, No. 2 (2019) 
of nanorods and nanotubes.science. 277(5334), p. 1971-1975. (1997).

29. Lupo, F., Kamalakaran, R., Scheu, C., Grobert, N., and Rühle, M., Microstructural investigations on zirconium oxide-carbon nanotube composites synthesized by hydrothermal crystallization. Carbon. 42(10), p. 1995-1999. (2004).

30. Mostafa, N.Y., Characterization, thermal stability and sintering of hydroxyapatite powders prepared by different routes. Materials chemistry and physics. 94(2-3), p. 333-341. (2005).

31. El-Bahy, G., Abdelrazek, E., Allam, M., and Hezma, A., Characterization of in situ prepared nanohydroxyapatite/polyacrylic acid (HAp/PAAc) biocomposites.Journal of Applied Polymer Science. 122(5), p. 3270-3276. (2011).

32. Venkatesan, J. and Kim, S.-K., Nano-hydroxyapatite composite biomaterials for bone tissue engineering - a review.Journal of biomedical nanotechnology. 10(10), p. 3124-3140. (2014).

33. Al-Sokanee, Z.N., Toabi, A.A.H., Al-Assadi, M.J., and Alassadi, E.A., The drug release study of ceftriaxone from porous hydroxyapatite scaffolds.Aaps Pharmscitech. 10(3), p. 772-779. (2009).

34. Pardo, B., Megademini, T., and André, J., X-UV synthetic interference mirrors: theoretical approach.Revue de physique appliquée. 23(10), p. 1579-1597. (1988).

35. Markovic, M., Fowler, B.O., and Tung, M.S., Preparation and comprehensive characterization of a calcium hydroxyapatite reference material.Journal of research of the National Institute of Standards and Technology. 109(6), p. 553-68. (2004).

36. Rameshbabu, N., Kumar, T.S., and Rao, K.P., Synthesis of nanocrystalline fluorinated hydroxyapatite by microwave processing and its in vitro dissolution study.Bulletin of Materials Science. 29(6), p. 611-615. (2006).

37. Venkatasubbu, G.D., Ramasamy, S., Ramakrishnan, V., and Kumar, J., Hydroxyapatite-alginate nanocomposite as drug delivery matrix for sustained release of ciprofloxacin.Journal of biomedical nanotechnology. 7(6), p. 759-767. (2011).

38. Yang, C.-C., Lin, C.-T., and Chiu, S.-J., Preparation of the PVA/HAP composite polymer membrane for alkaline DMFC application. Desalination. 233 (1-3), p. 137-146. (2008).

39. Yang, C.-C., Polymer Ni-MH battery based on PEO-PVA-KOH polymer electrolyte.Journal of Power Sources. 109(1), p. 22-31. (2002).

40. Yang, C.-C. and Lin, S.-J., Alkaline composite PEO-PVA-glass-fibre-mat polymer electrolyte for

J. Text. Color. Polym. Sci. 16, No. 2 (2019)
Zn-air battery.Journal of Power Sources. 112(2), p. 497-503. (2002).

41. Yang, C.-C., Synthesis and characterization of the cross-linked PVA/TiO2 composite polymer membrane for alkaline DMFC.Journal of Membrane Science. 288(1-2), p. 51-60. (2007).

42. Yang, C.-C., Chiu, S.-J., and Chien, W.-C., Development of alkaline direct methanol fuel cells based on crosslinked PVA polymer membranes.Journal of power sources. 162(1), p. 21-29. (2006).

43. Pan, Y. and Xiong, D., Preparation and characterization of nano-hydroxyapatite/polyvinyl alcohol gel composites. Journal of Wuhan University of Technology-Mater. Sci. Ed.25(3), p. 474-478. (2010).

44. Maheshwari, S.U., Samuel, V.K., and Nagiah, N., Fabrication and evaluation of (PVA/HAp/PCL) bilayer composites as potential scaffolds for bone tissue regeneration application.Ceramics International. 40(6), p. 8469-8477. (2014).

45. Firnanelty, S.S., and Charlena, synthesis of HApchitosan-PVA composites as injectable bone substitute material.Rasayan J. Chem.10(2), p. 570 - 576. (2017).

46. Mukherjee, S., Kundu, B., Chanda, A., and Sen, S., Effect of functionalisation of CNT in the preparation of HAp-CNT biocomposites. Ceramics International. 41(3), p. 3766-3774. (2015).

47. Maybody, J.J.F., Nemati, A., and Salahi, E., synthesis and properties of mwent-hap composites via solgel technique.Iranian Journal of Materials Science \& Engineering. 10(2), p. (2013).

48. Abrishamchian, A., Hooshmand, T., Mohammadi, M., and Najafi, F., Preparation and characterization of multi-walled carbon nanotube/hydroxyapatite nanocomposite film dip coated on Ti-6Al-4V by sol-gel method for biomedical applications: an in vitro study.Materials Science and Engineering: $C$. 33(4), p. 2002-2010. (2013).

49. BISWAL, S., preparation of Hydroxyapattiteporous Scaffold.Department of Ceramic Engineering $\mathrm{Na}$ tional Institute of Technology Rourkela - 769008. p. (2010).

50. Jegatheeswaran, S., Selvam, S., Ramkumar, V.S., and Sundrarajan, M., Novel strategy for f-HAp/ $\mathrm{PVP} / \mathrm{Ag}$ nanocomposite synthesis from fluoro based ionic liquid assistance: Systematic investigations on its antibacterial and cytotoxicity behaviors. Materials Science and Engineering: C. 67, p. 8-19. (2016).

(Received 9/ 7 / 2019 ; accepted $21 / 7$ / 2019) 


\section{التحضير والاراسات الطيفية والميكانيكية علي HAp النانو مسامية المحملة بمادة \\ MWCNTs}

جمال سعيد الباهى1 يحى محمد عباس2 ـ عبد الحميذ محمد طاهر حزمهـ1 نهى محمد جويلى1

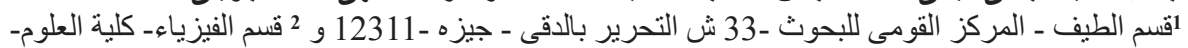
جامعة السويس -41522 - الاسماعلية ـ مصر .

\footnotetext{
ان الهدف الرئيسى من هذه الدر اسة هوتطوير طرق مختلفة لتحضير الهيدروكسى اباتيت ذات خصائص مسمامية

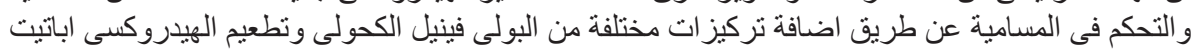

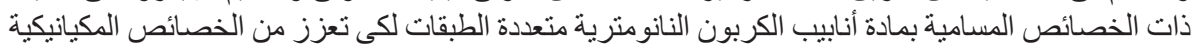

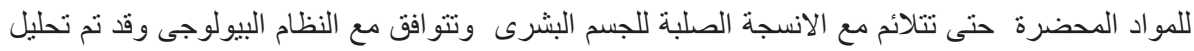

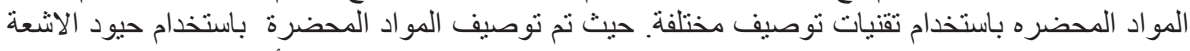

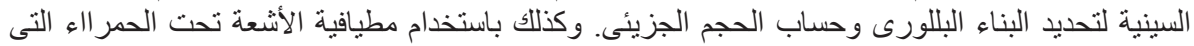

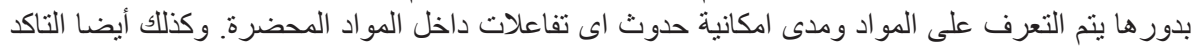

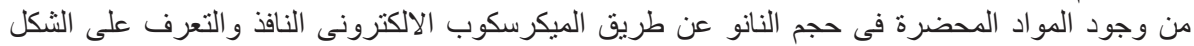

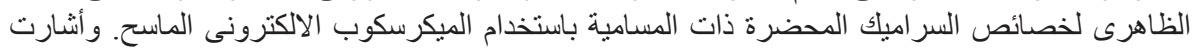

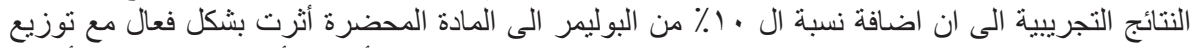

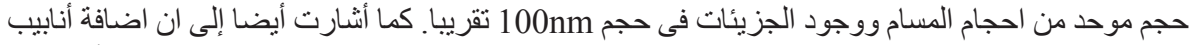

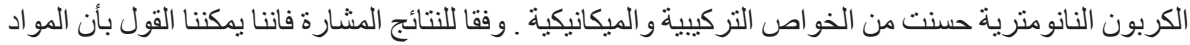

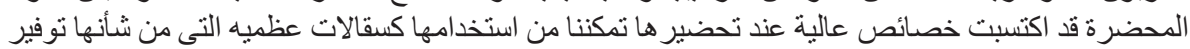
علاجات جديدة لتحسين الاداء الحيوى.
} 